\title{
㐘 \\ INTERFACES ENTRE ESPAÇO, GÊNERO E MARACATU-NAÇÃO
}

- LARISSA LIMA DE SOUZA'

Resumo: Fundamentando-se nos referenciais da Geggrafia Cultural Renovada, bem como consideranda contribuições de outras ciências saciais, a presente trabalho se debruça sobre a dinamicidade das Naçães de Maracatu. Esta investigação almeja compreender gengraficamente esta manifestação cultural com fortes vínculos religiosas, desvendanda suas territorialidades, seus lugares e itinerários simbólicas, madificados histaricamente, assim como as interfaces entre espaça e gênera em seu interior. A Geografia pade contribuir para a interpretação das realidades espaciais de mulheres e homens que encarnam o feminina no Maracatu-Nação, seja no batuque, na corte real, na sede, na cordão de catirinas au na comunidade em que se situam as grupas.

Palavras-chave: Maracatu-Nação, Gênero, Espaço.

\section{Introdução}

A cultura resulta de uma infindável construção pelos indivíduos, possuindo uma dimensão material e outra imaterial, relacionada aos significados (re)criados a partir de representações para atender às distintas demandas de um grupo ao longo do tempo (CLAVAL, 2006). Dentre essas representações, encontram-se as de gênero, dimensão da vida social e categoria útil à compreensão de 
fenômenos espaciais. Para a geógrafa Joseli Silva, baseada em Judith Butler, "gênero é uma representação que é vivenciada pelas performances dos sujeitos sociais que a experienciam através da vivência espacial cotidiana e concreta” (SILVA, 2008).

Nessa perspectiva, consideraremos a abordagem teórica da Geografia Cultural Renovada para, primeiramente, interpretarmos os símbolos das Nações de Maracatu. A propósito, nosso principal objetivo é refinar nossa investigação iniciada no Mestrado (LIMA, 2015a) e, especialmente, ampliar os estudos e debates geográficos acerca do Maracatu de Baque Virado, buscando compreender a realidade espacial das mulheres e homens que encarnam o feminino no MaracatuNação.

Para tal empreitada, utilizamos dados coletados a partir de vivências e palestras em que realizamos pesquisaparticipante, ao longo dos últimos dois anos, assim como dialogamos com a bibliografia que trata da problemática em questão. Situando-se em uma fronteira disciplinar, este trabalho combina contribuições de outras ciências sociais, como a História e a Antropologia, entre as quais o gênero e o Maracatu-Nação são temáticas que figuram há mais tempo.
O Maracatu-Nação, também conhecido como Maracatu de BaqueVirado $^{2}$, é uma manifestação cultural pernambucana caracterizada por um cortejo real ao som de um conjunto percussivo formado por batuqueiro(a)s, acompanhado por loas/toadas e danças as quais evidenciam tanto uma sonoridade (TINHORÃO, 2012) quanto uma corporeidade afrodiaspórica (GARCEZ, 2012). É a partir dos sons e da corporeidade, das cores e das vestimentas (LIMA, 2015), portanto dos geossímbolos (BONNEMAISON, 2012), que as Nações semiografam espaços, marcando sua identidade espacialmente. Portanto, sua dimensão geográfica está presente desde os lugares significativos para as Nações, seus itinerários, até a disposição de seus integrantes, geralmente distribuídos em alas (como o batuque, a corte real, os cordões de catirinas), por exemplo.

Diversos estudiosos se debruçaram sobre esta manifestação cultural e apontaram as Cerimônias de Coroação de Reis do Congo $^{3}$ como ponto de partida para se compreenderem as Nações de maracatu. Isabel Guillen e Ivaldo Lima demonstram o caráter movediço de tal concepção linear da história4. Ademais, os maracatus já surgem como cultura híbrida (CANCLINI, 2013), combinando elementos relacionados europeus, 
africanos, afro-brasileiros e afroameríndios. Ivaldo Lima também alega ser impossível uma delimitação espaçotemporal exata do maracatu.

Atualmente, as Nações se especificam por seu intenso vínculo com a religiosidade, evidenciado pelas referências espaciais e identitárias associadas aos territórios-terreiros (CORRÊA, A.M., 2004), onde são forjadas suas práticas religiosas. Esses terreiros podem ser de diversas modalidades, como os de Xangô (candomblé pernambucano), assim como de variantes afro-ameríndias, como a Jurema e a Umbanda (LIMA, 2005; SANTANA, 2012). De acordo com LIMA (2005), até o ano de 2007 não havia nenhum grupo de maracatu que estabelecesse relações com apenas um único terreiro.

Geralmente, esses territóriosterreiros (CORREAA, A.M., 2004) se situam em regiões periféricas constituídas por sítios urbanos pouco valorizados pelo capital e pelas elites locais - canais, áreas alagadiças, manguezais, topo de morros. Essas áreas receberam grande parte da população negra de baixa renda entre as décadas de 1930 e 1950, durante as quais havia intensa perseguição aos praticantes de religiões de matriz africana e a capital pernambucana recebia diversas políticas públicas de higienização e modernização urbanas. A fundação de terreiros nas áreas periféricas (Zona Norte de Recife e Oeste de Olinda) constituiu-se enquanto territorialidade, estratégia essencial para marcar a identidade dessa população e, consequentemente, para a continuidade das Nações de maracatu (CORRÊA, A.M, 2004; BONNEMAISON, 2012; FERREIRA, ANJOS, 2012).

Até hoje, é essa população de baixa renda que mantêm as Nações, dialogando com as heranças culturais, ao mesmo tempo em que as (re)ssignificam de acordo com suas necessidades e interesses cotidianos. (GUILLEN, 2004; LIMA, 2005; SANTANA, 2012; FERREIRA, ANJOS, 2012). Ivaldo Lima reforça, ainda, a importância de considerarmos a gama de atores envolvidos nos processos de criação, evolução, recolhimento e renovação pelos quais podem passar os maracatus-nação, processos estes que são influenciados por estruturas e/ou conjunturas socioeconômicas nos espaços em que ocorrem (LIMA, 2005).

Partindo de uma compreensão geográfica, a ideia de Nação se aproxima de território, na acepção de BONNEMAISON (2012), espaço marcado por geossímbolos e vivido a partir de subjetividades, onde são forjadas identidades para cada coletividade. A Nação vincula-se, portanto, a uma 
comunidade cujas especificidades socioeconômicas e, sobretudo, culturais as distinguem dos demais grupos (LIMA, 2005; FERREIRA; ANJOS, 2012). Ademais, como ressalta Julia Pittier Tsezanas, a Nação fornece significado ao maracatu e, simultaneamente, nomeia o "local que abriga o maracatu" (TSEZANAS, 2010:96).

\section{O gênero e a apropriação simbólica} do(s) espaço(s) no Maracatu-Nação

A reflexão acerca da relação existente entre Espaço, Maracatu e Gênero perpassa o processo de apropriação do espaço realizado pelos integrantes de tal manifestação cultural e seus respectivos personagens, seja no cotidiano ou no tempo da festa carnavalesca. Neste trabalho, privilegiaremos as personagens de gênero feminino, dentre as quais se encontram aquelas interpretadas por integrantes de ambos os sexos. Partindo dessa premissa, devemos nos indagar a fim de ampliar nossos horizontes na interpretação geográfica do Maracatu-Nação: A realidade espacial no Maracatu-Nação acompanha ou é influenciada pelas relações de gênero características da sociedade como um todo? Quais seriam as principais personagens femininas e seus territórios? Que personagens só podem ser interpretadas por mulheres? Quais e como são as corporeidades femininas? Existem diferenciações de funções na Nação baseadas no gênero? As funções desempenhadas por homens e mulheres possuem caráter religioso?

Elencamos cinco personagens para compor nosso quadro de interpretação das interfaces entre espaço, gênero e maracatu-nação: as baianas ricas, as catirinas, as rainhas, as calungas e as damas do paço. Cada uma delas domina e/ou circula por territórios específicos da Nação.

Um dos territórios conquistados pelas mulheres no maracatu é o batuque. De acordo com Jailma Oliveira e Lady Albernaz, as mulheres somente passaram a integrar a percussão dos maracatus a partir do surgimento dos chamados grupos percussivos ${ }^{5}$, pelo fato de a participação feminina nestes grupos ter grande efetividade. Nas palavras das autoras, "estas novas práticas parecem ter motivado as pessoas das camadas populares a redefinirem os espaços de homens e mulheres dentro dos maracatus tradicionais, sobretudo no batuque" (OLIVEIRA, ALBERNAZ, 2011:4-5). Atualmente, já há, inclusive, uma Nação de maracatu cuja posição de liderança comumente exercida pelo mestre de batuque, 
fundamental para a construção de uma identidade musical da nação (TSEZANAS, 2010), é ocupada por uma mulher. Tratase de Joana D`Arc da Silva Cavalcanté ${ }^{\text {, a }}$ mestra do Maracatu-Nação Encanto do Pina. É o mestre - ou no caso de Joana, a mestra - quem coordena o batuque e puxa as toadas de maracatu durante o cortejo.

Pode-se afirmar que, dentro de uma mesma ala no cortejo, pode haver uma diferenciação de gênero, como salientam OLIVEIRA e ALBERNAZ (2011), a respeito de uma "classificação dos instrumentos por gênero". As alfaias estariam associadas ao masculino e os abes/agbês associados ao feminino, exigindo, portanto, uma corporeidade que exalta gestualidades e expressões faciais diferenciadas (OLIVEIRA, ALBERNAZ, 2011).

No Maracatu-Nação, o feminino é encarnado, também, através das corporeidades de homens travestidos de mulher, prática igualmente presente em outras manifestações culturais, como aruendas, cambindas, maracatus de lança, possivelmente com significados distintos entre si e que devem ser investigados (LIMA, 2005). Nas Nações, esses homens travestidos geralmente interpretam personagens femininas, especialmente a personagem baiana rica ou orixás femininos (OLIVEIRA, ALBERNAZ, 2011), como
Oxum e Iansã, por exemplo. De acordo com Maurício Soares, baiana rica do Maracatu-Nação Estrela Brilhante de Recife, essas personagens eram chamadas, outrora, de "baianas de luxo", devendo entrar devidamente vestidas na avenida, ou seja, com roupas e acessórios exuberantes e saltos de tipo "Luís XV" (Ver Figura 1).

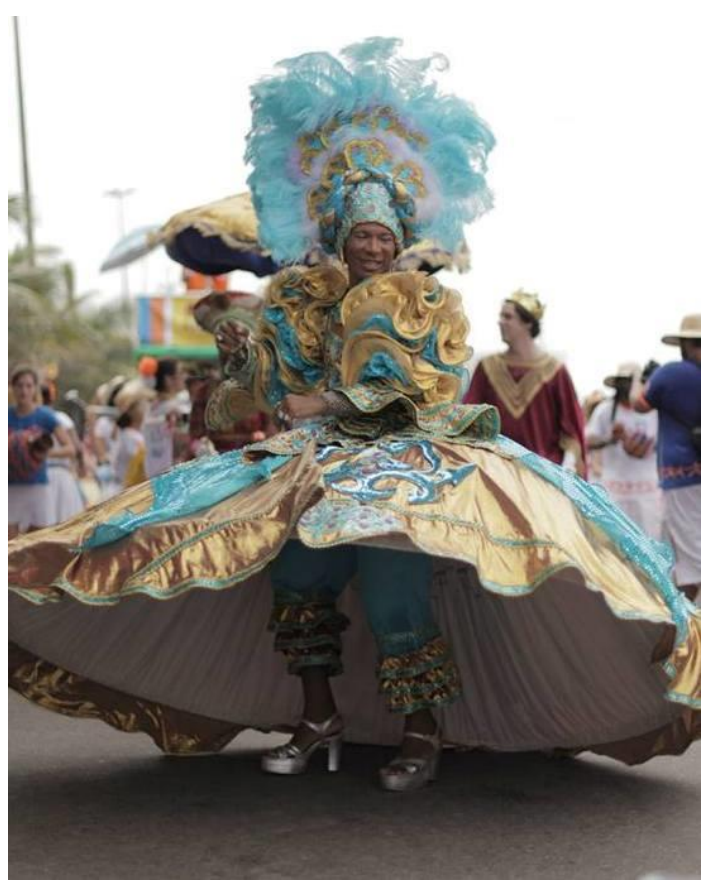

Figura 1: Mestre Maurício Soares, baiana rica da Nação Estrela Brilhante de Recife, no cortejo carnavalesco do grupo percussivo Rio Maracatu, Rio de Janeiro, 2015. Fonte: Autor - Steph Munnier.

$\mathrm{Na}$ perspectiva das autoras OLIVEIRA e ALBERNAZ (2011), além do batuque, a corte real é outro espaço no qual parece existir certa legitimidade para os homens ocuparem-no. Ao contrário da vivência espacial cotidiana das travestis, acompanhada de "muitas feridas e 
rejeições", sendo "comum que elas circulem pela cidade apenas no período da noite, mais associado às práticas sexuais comerciais que a maioria delas está praticamente condenada socialmente a desempenhar" (SILVA, 2008), no Maracatu-Nação os homens que se travestem, dentre os quais diversos homossexuais, são aceitos no nobre território da corte real. Tal aceitação, por sua vez, se relaciona tanto com a atenção que despertam junto ao público, quanto com as práticas religiosas das Nações, pois, se no terreiro ao qual o maracatu se filia, a autoridade religiosa permite a travestilidade quando da incorporação do orixá, a Nação trará homens interpretando baianas ou as divindades femininas que

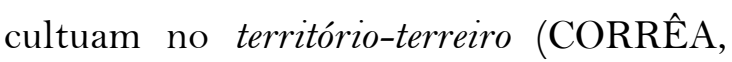
A.M., 2004) quando percorre as ruas (OLIVEIRA, ALBERNAZ, 2011).

Ao se transfigurarem em baianas ricas ou em orixás femininos, os homens travestidos costumam exaltar a feminilidade através de uma "exuberância de seu gestual e performance corporal" (SILVA, 2008). Tal gestualidade é ensinada, por exemplo, em oficinas de dança ministradas por mestres das nações em demais estados brasileiros, ou mesmo fora do Brasil. Maurício Soares, por exemplo, em uma oficina realizada em Novembro de 2015 no Rio de Janeiro, selecionava toadas (músicas) associadas a orixás femininos, como o canto para Oxum, e sugeria que nós, participantes, dançássemos de maneira feminina e sensual, e que nos exibíssemos ao máximo, utilizando bastante os braços, os ombros e as mãos com graciosidade. OLIVEIRA e ALBERNAZ (2011), a respeito da corporeidade das baianas ricas, abordam a influência do simbolismo que essas personagens trazem, revelando a desigualdade entre mulheres e homens travestidos no Maracatu-Nação.

Essa desigualdade envolve a interface entre espaço, gênero e sexualidade. Associadas à ideia de "mulher fatal" e ao "perigo da rua" (OLIVEIRA, ALBERNAZ, 2011), os homens que se travestem de baianas ricas costumam exaltar sua feminilidade e sua sexualidade, acompanhadas de "força" (física e em termos de coragem), práticas e comportamentos condenados às mulheres da Nação que desejam ser respeitadas, devendo "se ater aos tipos canônicos para as mulheres brasileiras de forma geral, e para as mulheres das comunidades na qual o maracatu se situa" (OLIVEIRA, ALBERNAZ, 2011:11). As autoras em questão reforçam o fato de os homens não se envergonharem por "serem da rua", visto que este sempre foi seu território, ao 
contrário das mulheres, cujo território por excelência seria a casa.

Outra figura feminina a qual permite a travestilidade no MaracatuNação, mas comumente interpretada por mulheres, é a catirina, igualmente conhecida como catita ou como baiana de cordão. Tais personagens simbolizam as mucamas, escravas as quais viviam próximas a seu senhorio. Geralmente, desfilam com vestimentas iguais (saias floridas, sem armações, blusas lisas da Nação ou do grupo percussivo, turbantes, acessórios para abrilhantar como cordões e pulseiras de contas), como aponta GARCEZ (2012). A outra nomenclatura associada a essas personagens se deve à organização espacial engendrada durante os cortejos: as catitas formam dois grandes cordões, em fila indiana, protegendo os demais membros das Nações, principalmente os integrantes da corte real. As catitas "cortam" os cortejos carnavalescos das Nações, permanecendo até o final do desfile na avenida. Ao contrário dos movimentos mais comedidos da Corte (princesas, rainha, damas de paço), os quais buscam simbolizar a realeza, a corporeidade das catirinas é mais livre e mais enérgica, inclusive em algumas Nações, elas dançam descalças (em uma associação com a corporeidade das escravas).
“Nagô, Nagô/Nossa rainha já se coroou..."?: o poder feminino (espiritual e simbólico) nas Nações

Em um cortejo de MaracatuNação, cada personagem é importante e uma das personagens obrigatórias e de maior expressividade simbólica é a rainha. Seu caráter central deve-se tanto ao seu simbolismo, associado à Coroa, quanto às suas responsabilidades religiosas (GUILLEN, 2004; OLIVEIRA, ALBERNAZ, 2011). A majestade deve ser acompanhada pelo rei e ambos devem portar certos símbolos da realeza, quando do cortejo carnavalesco: o pálio (carregado pelo escravo), o cetro, a espada, a capa, a coroa.

Julia Pittier Tsezanas (2010) revela que a rainha seria a principal referência e liderança de uma Nação, estando envolvida e presente em sua Nação ao longo do ano e assumindo as decisões mais importantes para o seu grupo. Ademais, a rainha atua politicamente junto às instituições culturais e aos órgãos oficiais envolvidos no processo de produção cultural (TSEZANAS, 2010) e é a única pessoa que pode substituir o mestre de batuque na função de entoar as loas/toadas de sua Nação na avenida ${ }^{8}$. 
Coroar-se em ritual público configura uma condição para o reconhecimento do título de rainha, cujo grupo se legitima em relação às demais Nações de maracatu e ao "povo de santo", pois apenas uma mãe de santo pode ser coroada (GUILLEN, 2004; OLIVEIRA, 2011; TSEZANAS, 2010). Outrossim, a coroação é uma "solenidade dúplice" (GUILLEN, 2004), em que se confirma o poder real através da entrega dos símbolos reais, ao mesmo tempo em que ocorre a unção de quem será coroada(o). Nesse sentido, quem terá o poder ou a legitimidade para coroar (pai de santo, mãe de santo ou padre) também é discutido.

O ritual de coroação sofreu alterações em seus significados ao longo do tempo, e esse processo envolveu, também, a importância de onde ocorrerá a coroação. De acordo com Roberto Lobato Corrêa, o simbolismo de determinados lugares apropriados por um grupo pode se relacionar tanto à afirmação do "status" ou da "identidade étnica ou religiosa" deste grupo (CORRÊA, 2008). Até a primeira metade do século XIX, as coroações ocorriam no interior da Igreja de Nossa Senhora do Rosário, tendo a última dessas eleições promovidas pela Igreja Católica ocorrido em 1848 (GUILLEN, 2004). No mesmo trabalho, a autora salienta que, quando a Igreja passa a proibir a prática de manifestações da cultura popular no interior de seus templos e deixa de sacralizar reis e rainhas, as coroações passam a ser realizadas por integrantes das Nações, "possivelmente em frente à Igreja de Nossa Senhora do Rosário no bairro de Santo Antônio" (GUILLEN, 2004:42). Essa realização preferencial do ritual de coroação na frente desta igreja se consolidou enquanto tradição entre os anos de 1930 a 1945, notavelmente uma fase de intensa repressão aos maracatus e às religiões afro-descendentes no Recife (GUILLEN, 2004).

No decorrer do século XX, esse ritual de coroação de rainhas de maracatu ocorreu pontualmente, a despeito da proibição da Igreja Católica (GUILLEN, 2004) mencionada anteriormente. No século XXI, Isabel Guillen aponta apenas duas coroações, ocorridas em 2002 e 2003: a de Dona Marivalda, rainha do Estrela Brilhante de Recife, e a de Dona Ivanize, do Encanto da Alegria, respectivamente. A coroação de Marivalda foi realizada por Dona Elda, rainha coroada da Nação Porto Rico, e ocorreu em frente à Igreja de Nossa Senhora do Rosário, motivo de exaltação através de toadas. De acordo com Marivalda, sua coroa pode ser reformada ao longo do tempo, mas sem deixar de possuir a cor do orixá da rainha, 
para que se mantenha a tradição ${ }^{11}$. Já a coroação de Ivanize foi feita por seu pai de santo no Pátio do Terço, lugar de grande expressividade simbólica - relacionada à memória da escravidão - localizado no centro histórico de Recife e considerado “o mais importante ponto de encontro das nações” (SANTANA, 2012:79) no carnaval.

Podemos afirmar que parte da relevância que a rainha possui para sua Nação relaciona-se a uma referência espacial, pois "a nação é uma pequena comunidade, não raro sua sede é a própria casa da rainha." (TSEZANAS, 2010:95. Grifos nossos.). É na sede em que se dão os encontros, o ir e vir de membros da Nação e visitantes, seja para festas, rituais, afinação e confecção de instrumentos, elaboração de adereços e vestimentas, ou mesmo para comer, conversar ou pedir conselhos a rainha (TSEZANAS, 2010), ou seja, é um espaço permeado por relações e onde constituem-se identidades.

É a rainha - mesmo que seja apenas iniciada (no candomblé ou na jurema) e não seja mãe de santo- quem assume, igualmente, as atribuições religiosas précarnavalescas, no intuito de que sua Nação esteja protegida ao longo da festa momesca. Podemos citar como exemplos dessas obrigações espirituais aquelas realizadas para os tambores e para as calungas (TSEZANAS, 2010). Seja no Xangô ou na Jurema, esse ritual de preparação das calungas é sagrado e restrito, ocorrendo no território-terreiro (CORRÊA, A.M., 2004). Geralmente, as bonecas "ficam guardadas o ano inteiro em um recinto especial, geralmente na sede da nação. Quando a sede do maracatu coincide com um terreiro de candomblé, as bonecas ficam guardadas no pegi (o 'altar' dos orixás)” (TSEZANAS, 2010:113. Grifos nossos.), sendo cada calunga regida por um orixá específico. No ritual de preparação, canta-se para todos os orixás (de Exu a Oxalá) ${ }^{12}$.

As calungas são bonecas pretas, feitas de madeira ou cera, e encarnam cargas espirituais de antigas rainhas da Nação. Por materializarem esse "axé" dos antepassados, as bonecas recebem nomes de pessoas já falecidas, convidadas a participar novamente dos "trabalhos" (GARCEZ, 2012) junto aos seus por meio de consultas espirituais nas quais se utiliza o jogo de búzios (LIMA, 2015b). Elas figuram entre os principais símbolos de uma Nação, denotando a proteção dos ancestrais aos seus membros e à coletividade. Por seu caráter sagrado, só podem ser tocadas e/ou carregadas durante os cortejos e apresentações fora do território-terreiro (CORRÊA, A.M., 
2004) pela rainha ou pelas chamadas damas de paço (Ver Figura 2).

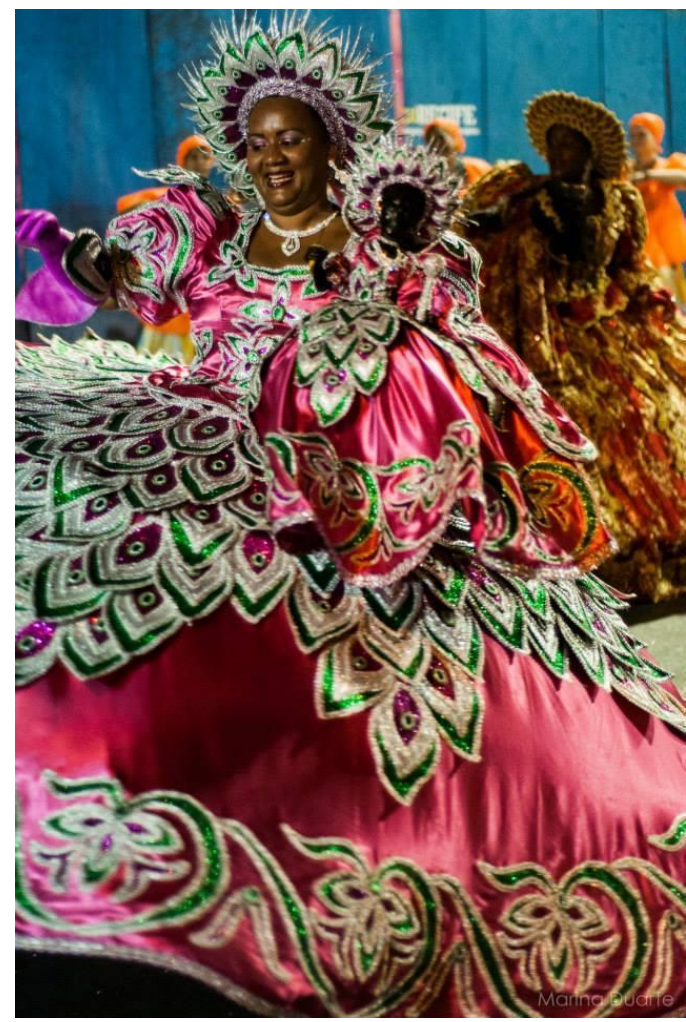

Figura 2 - Dama de Paço dançando com Dona Joventina, uma das calungas da Nação Estrela Brilhante de Recife, no cortejo carnavalesco em Recife, 2015. Fonte: Autora - Marina Duarte

As damas de paço são, necessariamente, mulheres escolhidas por meio da consulta com búzios, no terreiro da Nação. Como as calungas são vestidas com as cores de seus respectivos orixás, as roupas das Damas de Paço devem ser idênticas às de suas bonecas (LIMA, 2015b). Suas roupas são exuberantes vestidos no estilo da corte europeia, mas sofreram mudanças ao longo do tempo, ganhando volume, através de armações de metal e do aumento do comprimento.
Possivelmente, por questões estéticas ou, até mesmo, pelas regulações impostas pela Federação Carnavalesca, responsável pelo julgamento das Nações no dia do cortejo carnavalesco. Seu poder associado à religiosidade fica evidenciado pela posição de destaque ocupada pelas damas de paço com as calungas nos cortejos. Elas vão, preferencialmente, à frente da Nação, dançando e levantando as calungas, para que o grupo seja abençoado pela energia de seus ancestrais ali presente.

\section{Algumas considerações...}

As Nações de Maracatu apresentam grandes possibilidades para a investigação geográfica. A Geografia pode contribuir, por exemplo, para a interpretação das realidades espaciais de mulheres e homens que encarnam o feminino no Maracatu-Nação, questionando-se acerca dos significados de seus geossímbolos, assim como se debruçando sobre sua organização espacial interna, seja no batuque, na corte real, na sede, no cordão de catirinas ou na comunidade em que se situam os grupos. Vimos que a espacialidade cotidiana, desigual em termos de gênero, pode influenciar a que ocorre no MaracatuNação; no entanto, não é determinante, pois este se organiza, também, a partir de 
territorialidades sagradas associadas aos territórios-terreiros em que suas práticas religiosas acontecem.

\section{NOTAS}

1 Mestre em Geografia pelo Programa de PósGraduação em Geografia da Universidade do Estado do Rio de Janeiro (PPGEO/Uerj). Licenciada e Bacharel em Geografia pelo Instituto de Geociências da Universidade Federal Fluminense (IGEO/UFF). Professora Assistente do Departamento de Educação, Sociedade e Conhecimento da Faculdade de Educação da Universidade Federal Fluminense (SSE/FEUFF). E-mail: larissalima_uff@yahoo.com.br.

2 Baque designa tanto o conjunto de batuqueiros, quanto a batida ou ritmo de maracatu, havendo diferenciações a partir da marcação principal, dando origem a classificações distintas, como “parada”, "trovão”, “de Luanda” ou “de marcação”, "malê". Dentre os instrumentos percussivos utilizados no maracatu estão: alfaias/bombos/tambores, caixas/tarois, agbês/xiquerês, gonguês/agogôs, ganzás/mineiros, entre outros.

${ }^{3}$ Para mais informações acerca das cerimônias de Coroação de Reis e Rainhas do Congo, realizadas entre s séculos XVII e XIX no Brasil, ver SOUZA (2002, 2005), TINHORÃO (2012).

4. Maracatus e reis do Congo foram contemporâneos - inclusive disputando entre si -, sobretudo na segunda metade do século XIX, quando os primeiros se distanciam da Igreja Católica (LIMA, 2005; GUILLEN, 2004).

${ }^{5}$ Os grupos percussivos tocam e cantam o baque virado, nem sempre acompanhados por danças, não possuindo vínculo religioso como ocorre nas
Nações pernambucanas. Estão presentes em diversos estados brasileiros e, até mesmo, fora do Brasil, evidenciando um processo de expansão do maracatu. Para mais informações, consultar LIMA (2015a).

${ }^{6}$ A mestra Joana é a única mestra de Maracatu do Brasil e é, ainda, a responsável pela idealização e pela regência do primeiro e úncio grupo percussivo de Maracatu de Baque Virado formado integralmente por mulheres, o grupo Baque Mulher, o qual desenvolve uma militância a favor da luta das mulheres.

7 Toada de Maracatu de Domínio público.

8 Informação fornecida pelo Mestre Maurício Soares, baiana rica do Estrela Brilhante de Recife, durante palestra no Rio de Janeiro, em Novembro de 2015 .

9 Como exemplos dessa condição esporádica ao longo do século XX, GUILLEN (2007) aponta as coroações das rainhas: do Maracatu Dois de Ouro, realizada pelo Leão Coroado no ano de 1922, em frente à Igreja de Nossa Senhora do Rosário; de Dona Santa, rainha do Elefante coroada em 1947, permanecendo no posto até o ano de 1962; e de Dona Madalena, rainha do Estrela Brilhante de Recife, na década de 1970.

10 Um exemplo é toada de autoria de Mestre Walter França, da Nação Estrela Brilhante de Recife, em que se entoa: "Foi na Virgem do Rosário/ Que os nossos tambores zoou/Zoou, zoou/Marivalda, a rainha, ela já se coroou”.

11 Informação fornecida em palestra durante vivência de maracatu de baque virado, realizada no Rio de Janeiro e organizada pelo grupo Rio Maracatu. Para maiores referências, consultar LIMA (2015b).

12 Informação fornecida pelo Mestre Maurício Soares, baiana rica do Estrela Brilhante de Recife, durante palestra no Rio de Janeiro, em Novembro de 2015 . 


\section{REFERÊNCIAS BIBLIOGRÁFICAS}

BONNEMAISON, J. Viagem em torno do território. In: ROSENDAHL, Z.; CORREAA, R.L.(orgs.) Geografia Cultural: uma antologia. Rio de Janeiro: Eduerj, 2012. v. 1.

CANCLINI, Nestor García. Culturas Híbridas: estratégias para entrar e sair da modernidade. São Paulo: Editora da Universidade de São Paulo, 2013.

CORRÊA, A.M. Irmandade da Boa Morte como manifestação cultural afro-brasileira: de cultura alternativa à inserção global. Tese (Doutorado em Geografia) - Programa de Pós-Graduação em Geografia, Universidade Federal do Rio de Janeiro, Rio de Janeiro, ISBN n ${ }^{\circ} 381.535$. CDR, 2004.

CORRÊA, Roberto Lobato. A espacialidade da cultura In: OLIVEIRA, M. P.; NUNES, M. C. C.; CORRÊA, A.M. (orgs.). O Brasil, América Latina e o Mundo: Espacialidades Contemporâneas. Rio de Janeiro: Lamparina Editora, 2008.

CLAVAL, Paul. As abordagens da geografia cultural. In: CASTRO, Iná Elias de.; GOMES, Paulo C. C.; CORREAA, Roberto Lobato (orgs.). Explorações Geográficas. 2. ed. Rio de Janeiro: Bertrand Brasil, 2006. p.89-117.

FERREIRA, Cleison Leite; ANJOS, Rafael Sanzio Araújo dos. Territory of the Maracatus-Nação of Pernambuco: Preliminary Interpretation. Eletronic Magazine: Time - Technical - Territory, V.3, N.1, p.43-77, 2012.

GARCEZ, Laís Salgueiro. Os movimentos do Maracatu Estrela Brilhante de Recife: Os "trabalhos" de uma "nação diferente". Dissertação (Mestrado em Antropologia) - Programa de Pós-Graduação em Antropologia, Universidade Federal Fluminense, Niterói, 2012.

GUILLEN, Isabel Cristina Martins. Rainhas coroadas: história e ritual nos maracatus-nação de Recife.In: Cadernos de Estudos Sociais, Recife, vol.20,n.01, p.39-52, jan.- jun.2004.
LIMA, Ivaldo Marciano de França. MaracatusNação: ressignificando velhas histórias. Recife: Bagaço, 2005.

LIMA, Larissa. Vibrações, símbolos e lugares do Rio Maracatu. Dissertação (Mestrado em Geografia) Programa de Pós-Graduação em Geografia, Universidade do Estado do Rio de Janeiro, Rio de Janeiro, 2015a.

Relato da Vivência de Maracatu de Baque Virado com Rainha e Princesa do Maracatu Nação Estrela Brilhante do Recife: um Olhar Geográfico. In: Revista Discente Expressões Geográficas, Florianópolis, n.10, p.65-84, dez. 2015b.

OLIVEIRA, Jailma Maria; ALBERNAZ, Lady Selma Ferreira. Homens travestidos no MaracatuNação pernambucano: Trânsito entre masculinidade e feminilidade. In: XI Congresso Luso-Brasileiro de Ciências Sociais: Diversidades e (Des)igualdades. UFBA, Salvador, Bahia, 2011.

SANTANA, Paola Verri de. Maracatu-nação: Festa na cidade. Recife: Fundação de Cultura Cidade do Recife, 2012.

SILVA, Joseli Maria. A cidade dos corpos transgressores da heteronormatividade. Diez años de cambios en el Mundo, en la Geografía y en las Ciencias Sociales, 1999-2008. Actas del X Coloquio Internacional de Geocrítica, Universidad de Barcelona, 26-30 de mayo de 2008.

SOUZA, Marina de Mello e. Reis Negros no Brasil escravista: História da festa de coroação de Rei Congo. Belo Horizonte: Ed.UFMG, 2002.

.Reis do Congo no Brasil, séculos XVIII e XIX. Revista de História, São Paulo, n. 152, p. 7998, 2005.

TINHORÃO, José Ramos. Os sons dos negros no Brasil: Cantos, danças, folguedos: origens. 3. ed. São Paulo: Editora 34, 2012.

TSEZANAS, Julia Pittier. O Maracatu de Baque Virado: história e dinâmica social. Dissertação (Mestrado em História) - Programa de PósGraduação em História Social, Universidade de São Paulo, São Paulo, 2010. 


\section{INTERFACE BETWEEN SPACE, GENDER AND MACARATU-NATION}

ABSTRACT: BASED ON RENEWED CULTURAL GEOGRAPHY'S REFERENCES, AS WELL AS CONSIDERING CONTRIBUTIONS FROM OTHER SOCIAL SCIENCES, THIS WORK AIMS AT THE DYNAMICS OF MARACATU NATIONS. THIS RESEARCH LOOKS INTO UNDERSTANDING THIS STRONG RELIGIOUSLY TIED CULTURAL PRACTICE GEOGRAPHICALLY, UNMASKING THEIR TERRITORIALITIES, THEIR SYMBOLIC PLACES AND SYMBOLIC ITINERARIES, MODIFIED HISTORICALLY, AS WELL AS THEIR INTERFACES BETWEEN SPACE AND GENDER WITHIN. GEOGRAPHY CAN CONTRIBUTE TO THE INTERPRETATION OF WOMEN'S AND MEN'S SPATIAL REALITIES WHO EMBODY THE FEMININE IN MARACATU NATION, EITHER IN THE DRUMBEATS, THE ROYAL COURT, AT ITS HEADQUARTERS, IN CATIRINAS'S ROW OR IN THE COMMUNITY IN WHICH THE GROUPS ARE LOCATED.

KEY-WORDS: MARACATU-NATION, GENDER, SPACE.

\section{INTERFACES ENTRE ESPACIO, GÉNERO Y MARACATU-NACIÓN}

RESUMEN: FUNDAMENTÁNDOSE EN LOS REFERENTES DE LA GEOGRAFía CULTURAL RENOVADA, ASÍ COMO CONSIDERANDO CONTRIBUCIONES DE OTRAS CIENCIAS SOCIALES, EL PRESENTE TRABAJO SE CENTRA EN LA DINÁMICA DE LAS NACIONES DE MARACATU. ESTA INVESTIGACIÓN ANHELA COMPRENDER GEOGRÁFICAMENTE ESTA MANIFESTACIÓN CULTURAL CON FUERTES VíNCULOS RELIGIOSOS, DESVENDANDO SUS terRITORIALIDADES, SUS LUGARES E ITINERARIOS SIMBÓLICOS, MODIFICADOS HISTÓRICAMENTE, ASI COMO LAS INTERFACES ENTRE ESPACIO Y GÉNERO EN SU INTERIOR. LA GEOGRAFía PUEDE CONTRIBUIR A LA INTERPRETACIÓN DE LAS REALIDADES ESPACIALES DE MUJERES Y HOMBRES

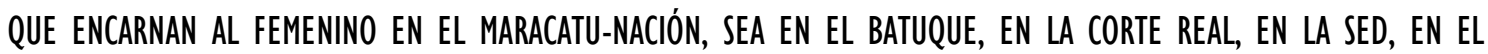
CORDÓN DE CATITAS O EN LA COMUNIDAD EN QUE SE SITÚAN LOS GRUPOS.

PALABRAS CLAVE: MARACATU-NACIÓN, GÉNERO, ESPACIO. 
